\title{
Petrogénesis de venas de cuarzo y cianita en rocas metapelíticas de la formación Silgará, región central del macizo de Santander en los Andes colombianos
}

\author{
Carlos A. Ríos R. ${ }^{1, *}$, Luis Carlos Mantilla F. ${ }^{1}$, Oscar M. Castellanos A. ${ }^{2}$ \\ ${ }^{1}$ Grupo de Investigación en Geología Básica y Aplicada (GIGBA), Escuela de Geología, \\ Universidad Industrial de Santander, Bucaramanga, Colombia \\ ${ }^{2}$ Grupo de Investigación en Geofísica y Geología (PANGEA), Programa de Geología, \\ Universidad de Pamplona, Colombia
}

\begin{abstract}
Resumen
Las rocas metamórficas de la formación Silgará (sensu lato), de edad pre-Devónico, aflorantes en la región central del macizo de Santander (Cordillera Oriental de Colombia), presentan venas hidrotermales de cuarzo y cianita ligeramente boudinadas, paralelas a la foliación metamórfica regional. Estas venas se consideran manifestaciones excepcionales, tanto por su restringida distribución en el contexto del Macizo de Santander, como por su composición y génesis. Los cristales de cianita se observan, 1) en la proximidad del contacto con las rocas metapelíticas encajantes (afectadas por metamorfismo en facies anfibolita, zona de la estaurolita-cianita), con una orientación paralela a la foliación metamórfica, lo cual indica un crecimiento progresivo durante la apertura de la vena, y 2) hacia el centro de la vena, exhibiendo una orientación al azar, lo cual sugiere un crecimiento sin un control de esfuerzos significativo. Con base en las relaciones litológicas y los estudios paragenéticos, es posible sugerir que el origen de estas venas hidrotermales se relaciona con la circulación o el escape de fluidos propios de eventos magmático-hidrotermales de edad Ordovícico?. (C) 2017. Acad. Colomb. Cienc. Ex. Fis. Nat.
\end{abstract}

Palabras clave: Colombia; Macizo de Santander; Formación Silgará; Venas hidrotermales; Cianita.

Petrogenesis of quartz-kyanite veins in metapelitic rocks of the Silgará Formation, central Santander Massif (Colombian Andes)

\begin{abstract}
The metamorphic rock of the Silgará formation (sensu lato), of pre-Devonian age, cropping out at the central region of the Santander massif (Colombian Eastern Cordillera), presents slightly boudinated hydrothermal quartz and kyanite veins parallel to the regional metamorphic foliation. These veins are considered as exceptional manifestations due to their restricted distribution in the context of the Santander Massif and their composition and genesis. Kyanite crystals are observed, 1) in the proximity to the contact with the wall metapelitic rocks (affected by amphibolite facies metamorphism, staurolite-kyanite zone), showing a direction parallel to the metamorphic foliation, which indicates a progressive growth during the opening of the vein, and 2) toward the center of the vein, exhibiting random orientation, which suggests a growth control without significant efforts. Based on lithological relationships and paragenetic studies, it is possible to suggest that the formation of these hydrothermal veins is related to the circulation or scape of hydrothermal fluids typical of magmatic-hydrotermal events of Ordovician? age. (C) 2017. Acad. Colomb. Cienc. Ex. Fis. Nat.
\end{abstract}

Key words: Colombia; Santander massif; Silgará formation; Hydrothermal veins; Kyanite.

\section{Introducción}

Las venas de cuarzo con presencia de polimorfos de $\mathrm{Al}_{2} \mathrm{SiO}_{5}$ ha sido reportada en terrenos metamorficos regionales (e.g., Yardley, et al., 1980; Stout, et al., 1986; Lang and Dunn, 1990; Nabelek, 1997; Whitney and Dilek, 2000; Widmer and Thompson, 2001; McLelland, et al., 2002; Putlitz, et al., 2002; Larson and Sharp, 2003; Sepahi, et al., 2004; Beitter, et al., 2008; Bucholz and Ague, 2010) y aureolas de contacto (e.g., Spear, 1982; Cesare, 1994; Okuyama-
Kusunose, 1994; Larson and Sharp, 2003; Sepahi, et al., 2004). La presencia de polimorfos de $\mathrm{Al}_{2} \mathrm{SiO}_{5}$ brinda valiosa información con relación a las condiciones de movilización de $\mathrm{SiO}_{2}$ y $\mathrm{Al}_{2} \mathrm{O}_{3}$ por fluidos en condiciones de deformación dúctil y pueden suministrar evidencias acerca de las

\footnotetext{
*Correspondencia:

Carlos A. Ríos R., carios@uis.edu.co

Recibido: 21 de junio de 2016

Aceptado: 18 de abril de 2017
} 
condiciones de PT de metamorfismo, la(s) fuente(s) más probable(s) de fluidos, y los mecanismos de formación de venas (e.g., Widmer and Thompson, 2001; Sepahi, et al., 2004). La determinación de la movilidad del Al durante el metamorfismo regional y la interacción fluido-roca han sido objeto de estudio en la literatura (e.g., Carmichael, 1969; Thompson, 1975; Grant, 1986; Verdes, et al., 1992; Lentz and Gregoire, 1995; Beitter, et al., 2008). Entre los primeros estudios, se destaca el trabajo de Carmichael (1969), el cual considera que el $\mathrm{Al}$ es generalmente relativamente inmóvil con relación a otros elementos, tales como $\mathrm{Na}, \mathrm{K}, \mathrm{Ca}, \mathrm{Mg}$ y Fe, durante la interacción fluido-roca (e.g., Verdes, $\boldsymbol{e t}$ al., 1992). Sin embargo, la ocurrencia de polimorfos de $\mathrm{Al}_{2} \mathrm{SiO}_{5}$ en venas de cuarzo y rocas alteradas adyacentes a estas venas revela algun grado de movilidad del Al durante el metamorfismo (e.g., Ague, 1995; Whitney and Dilek, 2000; Widmer and Thompson, 2001; Putlitz, et al., 2002; Larson and Sharp, 2003; Sepahi, et al., 2004; Allaz, et al., 2005; Beitter, et al., 2008). Por lo tanto, la movilidad del $\mathrm{Al}$ ha sido extensamente usada como una constante de referencia en estudios de transferencia de masa durante el metamorfismo regional (e.g., Thompson, 1975; Grant, 1986) y alteración hidrotermal (Lentz and Gregoire, 1995). No obstante, el relativo enriquecimiento en polimorfos de $\mathrm{Al}_{2} \mathrm{SiO}_{5}$ observados en las venas de cuarzo, con relación a la abundancia de cuarzo y otros silicatos u óxidos es un asunto aún incierto (Beitter, et al., 2008). Aquí enfocamos nuestra atención sobre la extraña ocurrencia de venas de cuarzo con cianita (KyQVs) en las rocas metapelíticas de la Formación Silgará que afloran en la región central del Macizo de Santander (RCMS) y su significado petrogenético. García, et al. (2005) reportan la ocurrencia de polimorfos de $\mathrm{Al}_{2} \mathrm{SiO}_{5}$ en diferentes localidades de esta región, aunque sin establecer su relación con la presencia de KyQVs. Caviedes y Gómez (2006) llevan a cabo un estudio petrológico de las KyQVs, estableciendo parámetros con relación a la formación de cianita en estas venas en una banda de cizallamiento. El objetivo del presente estudio es describir la ocurrencia de KyQVs en rocas metapelíticas de la zona de la estaurolitacianita de la Formación Silgará que afloran en la RCMS, discutir su formación y sus implicaciones petrogenéticas.

\section{Antecedentes y contexto geológico regional}

Las rocas metamórficas del basamento del MS (Figura 1) han sido agrupadas principalmente en las siguientes unidades litológicas: Complejo Neis de Bucaramanga, Esquistos del Silgará (sensu lato, s.l.) y Ortogneis (Ward, et al., 1973; Clavijo, 1994). Recientemente, Mantilla, et al. (2016), subdividen la unidad Esquistos del Silgará (s.l.) en: Esquistos del Silgará (sensu stricto; s.s.), Esquistos del Chicamocha y Filitas de San Pedro. Todas estas litologías se consideran de edad pre-Devónico, debido a que el registro sedimentario más antiguo del MS contiene fósiles de esta edad y es observado cubriendo localmente las unidades metamórficas referidas (Boinet, et al., 1985). Estudios geocronológicos recientes realizados en el MS, han permitido establecer que la unidad Neis del Bucaramanga tiene una máxima edad estratigráfica del Meso-Proterozóico (edad de depositación entre 1200-1300 Ma; según edades U-Pb en zircones detríticos), y ha sido afectada por eventos metamórficos que guardan relación temporal con los reportados para el cinturón orogénico Grenvilliano que afectó al margen Este de Laurentia, a finales del Meso-Proterozóico y comienzos del Neo-Proterozóico (entre 1100 y 980 Ma; Cordani, et al., 2005). La unidad Esquistos del Silgará (s.s.) se considera tiene una máxima edad estratigráfica del Neo-Proterozóico (máxima edad de depositación de 900 Ma), según edades $\mathrm{U}-\mathrm{Pb}$ de los zircones detríticos más jóvenes presentes en sus litologías siliciclásticas. Por otro lado, la unidad Esquistos del Chicamocha se considera tiene una máxima edad de depositación del Cambrico Medio ( 500 Ma). El máximo pico de metamórfico que afectó a estas dos unidades metamórficas (Esquistos del Silgará s.s. y del Chicamocha), se considera tuvo lugar durante el evento principal de la Orogenia Fammatiniana (localmente denominada QuetameCaparonensis; Ordovícico Temprano; 480-470 Ma). Con el desarrollo de la orogenia Fammatinina (evento orogénico principal), se relaciona el emplazamiento de granitoides sin-tectónicos (de edades entre 480-472 Ma), los cuales hacen parte de la denominada unidad metamórfica Ortoneis (Restrepo-Pace and Cediel, 2010; Mantilla, et al., 2012; Van der Lilej, et al., 2016). La unidad Filitas de San Pedro representa la unidad metamórfica más joven reconocida en el MS. Su máxima edad estratigráfica se considera Ordovícico Tardío (según edades U-Pb de los zircones detríticos más jóvenes presentes en sus litologías siliciclásticas, $>450$ Ma). El metamorfismo que afectó a esta unidad no ha sido determinado por métodos geocronológicos. No obstante, considerando (1) la presencia de unidades graníticas con moscovita ígnea y granate ocasional en el MS (rocas ligeramente peralumínicas de la serie calco-alcalina alta en potasio, agrupadas dentro de la unidad ígnea Granito de Durania), de edad Silúrico Temprano ( 442 Ma; según dataciones U-Pb en circones reportads por Botello, et al., 2014), (2) el contexto de emplazamiento sugerido por Botello, et al. (2014) para ésta unidad ígnea (mediante pulsos magmáticos generados durante un evento progresivamente cada vez más compresivo), y (3) la existencia de rocas sedimentarias del Devónico cubriendo estas litologías, es posible sugerir que el último evento de metamorfismo regional que afectó al MS, debió tener lugar principalmente durante el periodo comprendido principalmente entre finales del Ordovícico y Silúrico (Van der Lilej, et al., 2016; Mantilla, et al., 2016). Este evento tectono-termal, el cual dio lugar a litologías de más bajo grado de metamorfismo (e.g., fillitas y meta-sedimentitas), se relaciona con otro evento de metamorfismo regional, el cual ha sido denominado como evento orogénico Fammatiniano Menor (Mantilla et al., 2016). Un evento tectono-termal más reciente que el Fammatiniano ya referido para el MS, al parecer tuvo 


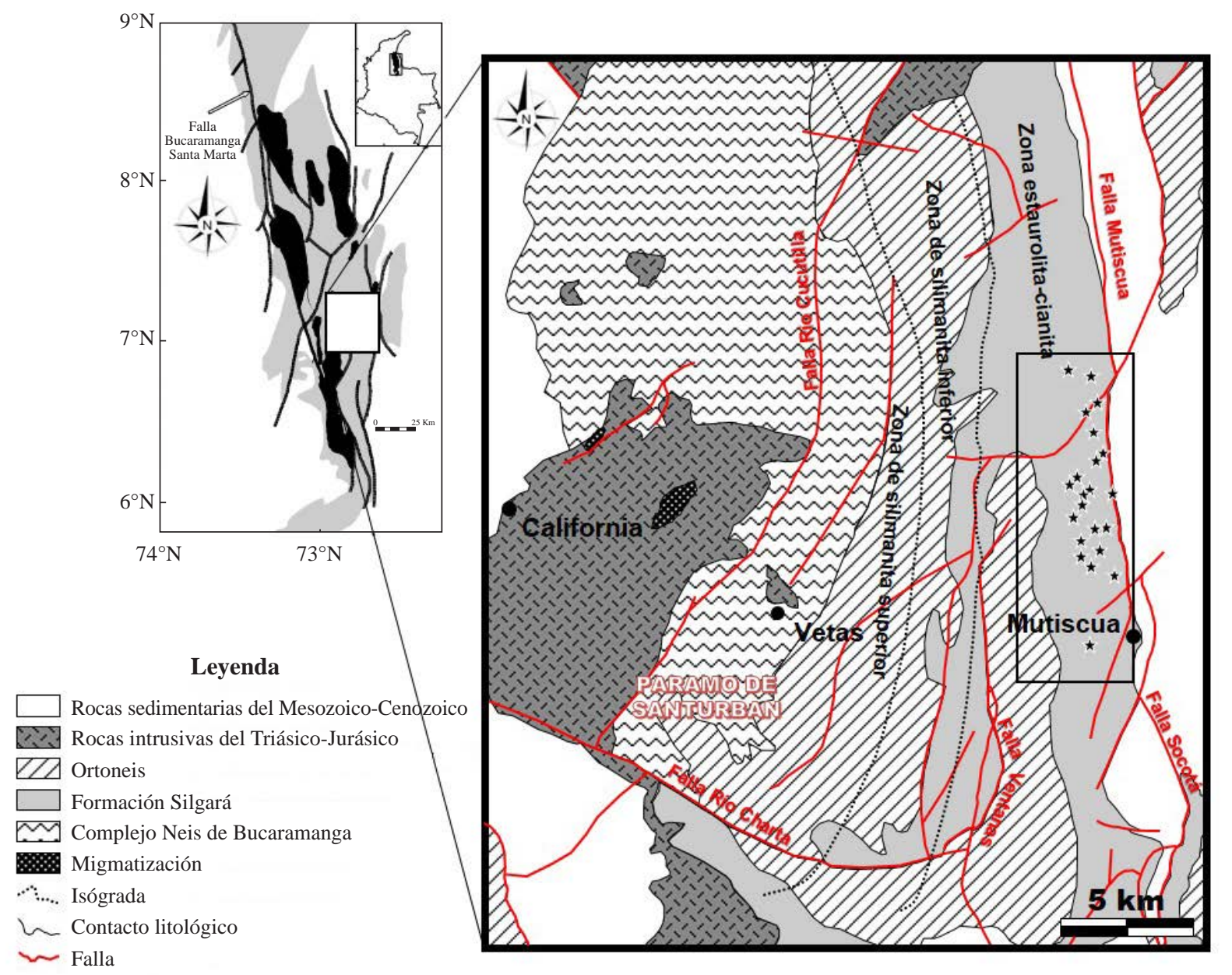

Figura 1. Izquierda, mapa geológico generalizado del Macizo de Santander (adaptado y modificado de Goldsmith, et al., 1971), mostrando la RCMS. Centro, esquema geológico-estructural generalizado de la RCMS (adaptado y modificado de Ward, et al., 1973, y García, et al., 2005), mostrando la localización del área de estudio y sitios de muestreo de KyQVs (indicados por estrellas negras).

lugar durante el Paleozóico Tardío (Silva, et al., 2004). Sin embargo, este evento no se acompañó de fenómenos propios de un metamorfismo regional, sino que generó localmente procesos de metamorfismo dinamo-térmico. Las litologías metamórficas que contienen las venas de cuarzo-cianita (KyQVs) objeto del presente estudio, han sido agrupadas como parte de la Formación Silgará (s.l.; siguiendo el sentido original de Ward, et al., 1973). No obstante, considerando la reciente propuesta de escisión para esta unidad (Mantilla, et al., 2016), es posible sugerir que las KyQVs se hospeden en la unidad Esquistos del Chicamocha. Sin embargo, debido a la falta de una mayor densidad de datos geocronológicos (y teniendo en cuenta que el máximo pico de metamorfismo para estas dos unidades referidas es el evento orogénico principal Fammatiniano, en adelante se hará referencia a las litologías hospedadoras de las KyQVs como Formación Silgará (s.l. Con base en las localidades donde afloran las rocas metamórficas del basamento del MS, en este se reconocen varias franjas de rocas metamórficas, tales como las franjas Piedecuesta-Aratoca, Pamplona-
Chitagá y Berlín-Silos-Mutiscua, entre otras (Ward, et al., 1973; Royero y Clavijo, 1994). La secuencia de rocas metamórficas de la Formación Silgará (s.l.), aflorante en la franja Berlín-Silos-Mutiscua, está limitada al oeste con la unidad Ortoneis, en contacto onduloso e irregular; al este con la Falla de Mutiscua, la cual pone en contacto a la Formación Silgará con la Formación Floresta (unidad sedimentaria más antigua del MS, de edad Devónico), y al sureste con la Falla de Socotá, la cual pone en contacto a la Formación Silgará con rocas sedimentarias de ambiente marino de edad Cretácica. Hasta la fecha, la única franja de rocas metamórficas del MS en la cual se han observado las KyQVs, corresponde a la franja Berlín-Silos-Mutiscua, la cual se localiza en la region central del MS (RCMS). Allí afloran rocas metapelíticas (esquistos micáceos con granate, estaurolita y cianita, con subordinado feldespato potásico y plagioclasa). Estas rocas son la litología huésped de las KyQVs. Estudios previos sobre las condiciones del evento metamórfico principal que ha afectado a estas rocas en la RCMS (e.g., Castellanos, 2001; Castellanos, et al., 2004, 
2008; García, et al., 2005), revelan que éste tuvo lugar en condiciones de presión intermedia y alta temperatura (metamorfismo tipo Barroviense). Apoyados en el esquema zonal (según presencia de minerales metamórficos índices) propuesto por otros autores (e.g., Ward, et al., 1970; García, et al., 2005), el área donde afloran las KyQVs, se proyecta en la zona metamórfica de la estaurolita-cianita, en donde las condiciones máximas de presión y temperatura alcanzadas, están en el rango de 6.1-8.5 kbar y 616-784 ${ }^{\circ} \mathrm{C}$ (García, et al., 2005). La trayectoria de PT en sentido horario para estas rocas, sugieren el desarrollo de un evento colisional, con engrosamiento cortical durante las primeras etapas de la colisión, seguido de una exhumación, resultando en una descompresión acompañada por calentamiento (García, et al., 2005). Asociado a este último evento (descompresión y calentamiento por adelgazamiento cortical), se relaciona la formación de porfidoblastos de andalucita y cordierita en algunos sectores de la RCMS. No obstante, no se descarta que algunos de estos minerales se relacionen con procesos propios de un metamorfismo de contacto, temporalmente coincidentes con el emplazamiento de cuerpos ígneos propios de los eventos magmáticos del Paleozóico o Mesozóico (?).

\section{Muestreo de campo y técnicas analíticas}

Las muestras de KyQVs se recolectaron durante el desarrollo de varios trabajos de campo realizados en los alrededores del municipio de Mutiscua (Norte de Santander) con estudiantes de la Escuela de Geología de la Universidad Industrial de Santander. La estrategia de muestreo consistió en tomar las KyQVs en diferentes afloramientos. Las muestras fueron caracterizadas inicialmente por estereomicroscopía, utilizando un equipo ZEISS modelo Stemi DV4, con el fin de determinar los rasgos a escala macroscópica de las KyQVs. El análisis petrográfico se llevó a cabo utilizando un microscopio de polarización trinocular Olympus BX-51, con sistema de fotomicrografía Nikon de alta resolución de 5.5 MegaPixeles y con software Nikon NIS-Elements de la Universidad de Pamplona, con el fin de observar los rasgos texturales y microestructurales. Las abreviaturas de los minerales utilizadas, son las propuestas por Kretz (1983). La cianita y las fases minerales asociadas en las venas hidrotermales se analizaron también por microscopía electrónica de barrido (SEM), utilizando un equipo QUANTA FEG 650 marca FEI, bajo las siguientes condiciones analíticas: aumento = 120-10000x, HFW = 4.97-5.97.0 $\mu \mathrm{m}$ and 1.99-2.49 mm, HV $=20 \mathrm{kV}, \mathrm{WD}=10.0-11.3$, señal $=$ BSE y Z Cont, detector $=$ BSED, detector EDS EDAX APOLO X con resolución de $126.1 \mathrm{eV}$ (en. Mn K $\alpha$ ).

\section{Resultados}

Relaciones litológicas. Las rocas metamórficas de la Formación Silgará (referida también en la literatura como unidad Esquistos del Silgará ó Unidad Esquistos del Silgará s.l.) en la RCMS presentan actitudes espaciales variables (al sur, los rumbos son NE, con buzamientos NW; al norte, los rumbos son NW, con buzamientos NE), y muestran evidencias que reflejan que han sido afectadas por múltiples deformaciones. Estas rocas metamórficas están representadas principalmente por rocas metapelíticas, las cuales presentan delgadas intercalaciones de metabasitas y rocas matacarbonatadas y calcosilicatadas. Las rocas metapelíticas en la zona de la estaurolita-cianita incluyen esquistos micáceos, esquistos granatíferos, esquistos con granate + estaurolita ( \pm cianita \pm andalucita \pm silimanita), y cuarcitas micáceas. Las KyQVs se encuentran hospedadas en esquistos micáceos con granate + estaurolita \pm cianita. Las venas de cuarzo son esencialmente monominerales, aunque en algunos casos presentan cianita + cuarzo. Los contactos con las rocas encajantes son netos, aunque en algunos sectores se observa una delgada zona de transición (hasta de $1 \mathrm{~cm}$ de espesor) entre las KyQVs y las rocas encajantes, dentro de la cual es común observar enriquecimiento en muscovita o biotita, dependiendo del tipo de mica predominante en las rocas encajantes. Las KyQVs presentan espesores aproximadamente desde $1 \mathrm{~cm}$ hasta $1 \mathrm{~m}$, y se caracterizan por estar boudinadas (discontinuas) y formar lentes asimétricos concordantes con la foliación metamórfica de las rocas encajantes. No obstante, otras pueden seguirse a escala de afloramiento hasta por varios metros. A escala de afloramiento, las venas están aisladas y no forman redes o enjambres de venas interconectadas. La cianita es encontrada, particularmente en y alrededor de venas de cuarzo. Este mineral excepcionalmente desarrolla agregados de cristales de hasta de $3.5 \mathrm{~cm}$ de longitud, de color azul claro ligeramente verdoso. En algunos casos, la cianita parece haber nucleado hacia el contacto con la roca encajante, en donde la cianita ha crecido paralelo a las paredes de las venas, aunque es más común observar la cianita en cristales orientados al azar completamente contenidos en las venas de cuarzo. Aunque las venas de cuarzo están distribuidas a través de toda el área de estudio, las KyQVs al parecer se encuentran solo dentro de esquistos micáceos alumínicos. Las figuras 2 y 3 ilustran ejemplos de la ocurrencia de este tipo de venas en esquistos micáceos de la Formación Silgará.

En general, los cristales azules de cianita de dimensiones centimétricas exhiben su eje c más desarrollado paralelo al borde de las venas de cuarzo, aunque dentro de ésta presentan una orientación al azar (Figura 4), similar a lo reportado por Allaz, et al. (2005), quienes consideran que los cristales de cianita orientados de forma paralela a la lineación mineral de las rocas encajantes, indican un crecimiento progresivo durante la apertura de la vena, mientras que los cristales de cianita que exhiben una orientación al azar, sugieren un crecimiento sin un control de esfuerzos significativo.

No existe evidencia de la existencia de andalucita o silimanita en estas venas o rellenando fracturas en cianita. No obstante, en una muestra recolectada "ex situ" se observa un intercrecimiento entre los tres polimorfos de $\mathrm{Al}_{2} \mathrm{SiO}_{5}$, con un predominio de la cianita, la cual ha sido parcialmente reemplazada por muscovita. La Figura 1S, https://www. raccefyn.co/index.php/raccefyn/article/downloadSuppFile/ 


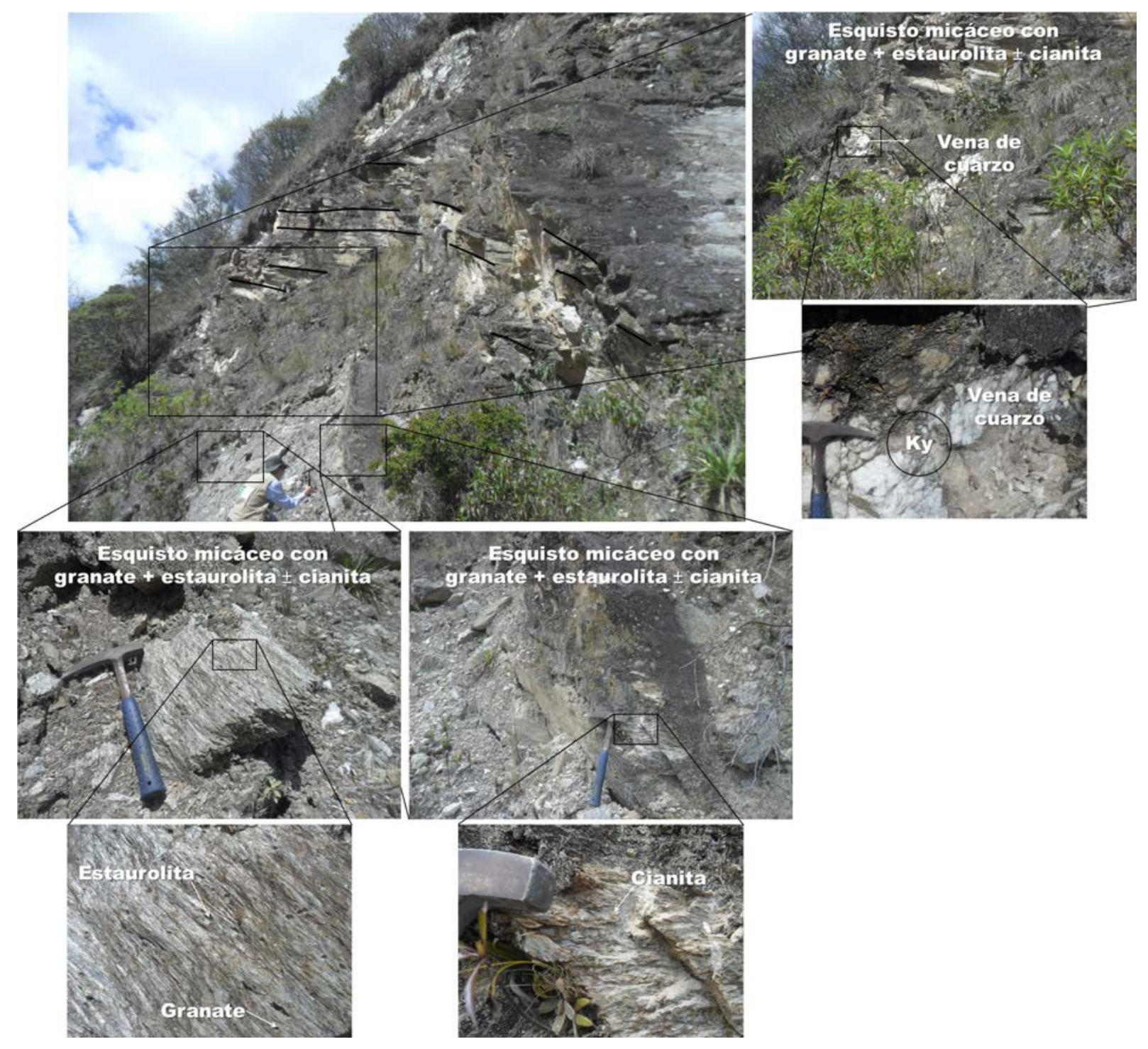

Figura 2. Fotografía de afloramiento de esquistos micáceos con granate + estaurolita \pm cianita, mostrando la ocurrencia de agregados de cianita en el cuello de una vena de cuarzo boudinada.

385/1918, ilustra la ocurrencia de intercrecimientos de cianita con muscovita, así como las relaciones texturales entre los polimorfos de $\mathrm{Al}_{2} \mathrm{SiO}_{5}$.

\section{Petrografía}

Petrografía de la roca encajante. La roca encajante de las KyQVs está representada por esquistos pelíticos de la Formación Silgará, los cuales presentan una estructura esquistosa bien definida con orientación preferencial de los constituyentes micáceos (biotita y muscovita), y se caracterizan por presentar una textura básicamente porfidoblástica con matriz granolepidoblástica. Estas rocas revelan un metamorfismo retrógrado, el cual promueve procesos de hidratación (y consecuentemente también alteraciones hidrotermales), tales como reemplazamiento parcial de granate, biotita y estaurolita por clorita, y plagioclasa y estaurolita por sericita (Castellanos, et al., 2008). La petrografía y química mineral de las rocas metapelíticas de la Formación Silgará ha sido reportada en los trabajos previos (e.g., Campos, 1999; Castellanos, 2001; Castellanos, et al., 2004, 2008; García, et al., 2005). Con base en la información de estos estudios previos y los resultados de este trabajo, discutimos los rasgos composicionales y texturales de estas rocas, los cuales son de gran importancia para el entendimiento de las condiciones y mecanismos de formación de venas hidrotermales y su relación con las rocas encajantes. Las venas de cuarzo son comunes en la Formación Silgará y algunas contienen cristales de cianita. Los esquistos están compuestos por cuarzo, estaurolita, granate, biotita, muscovita, plagioclasa, grafito y turmalina. El granate generalmente ocurre como porfidoblastos típicamente de grano fino, especialmente en dominios ricos en cuarzo (esquistos silíceos de Castellanos, 2001), los cuales exhiben zonación sectorial textural y química 


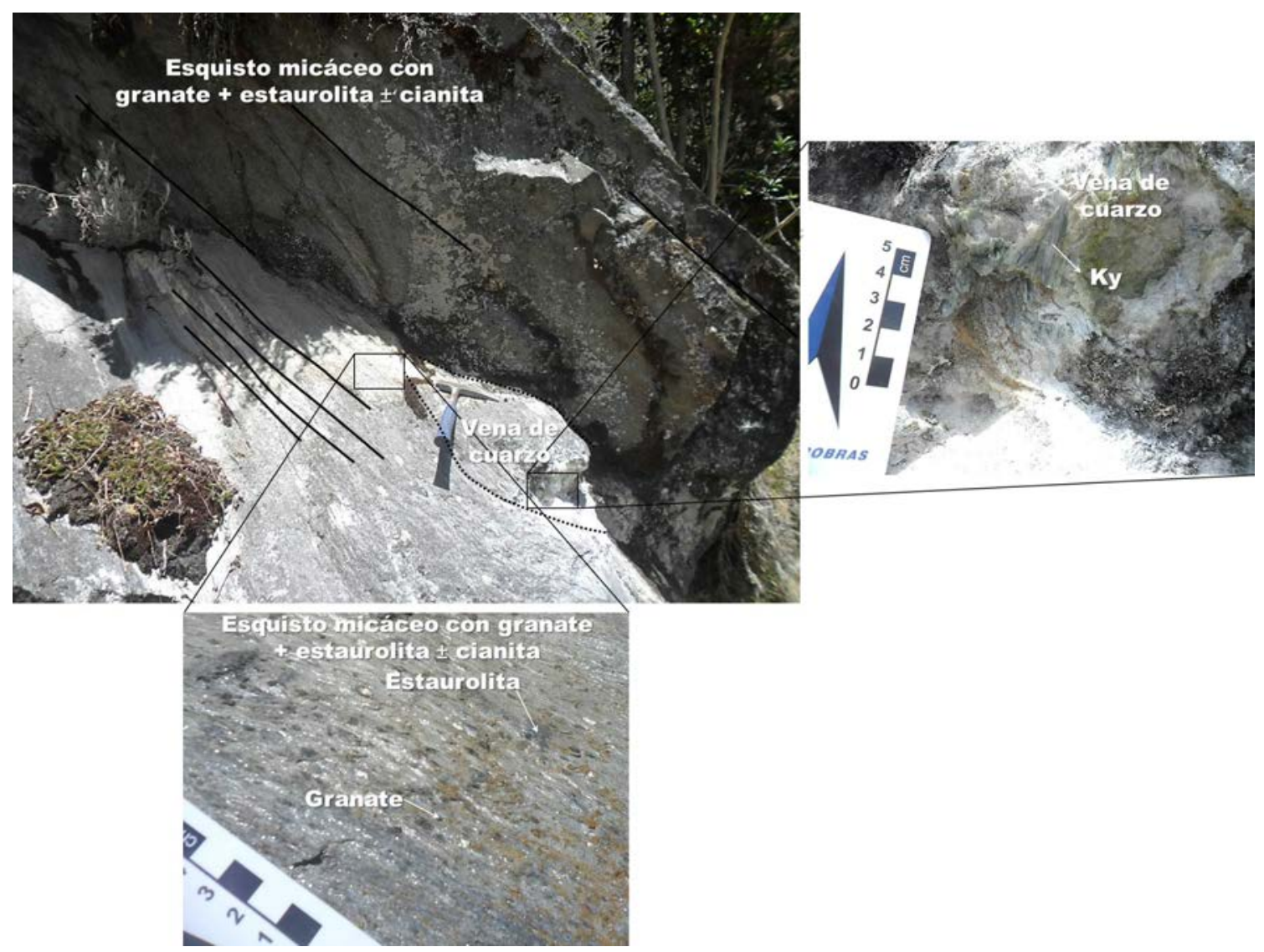

Figura 3. Fotografía de afloramiento de KyQVs de geometría lenticular y paralela a la foliación KyQVs metamórfica de esquistos micáceos con granate + estaurolita \pm cianita.

(Castellanos, et al., 2008). No obstante, este mineral ocurre también como cristales euhedrales parcialmente incluidos en estaurolita o como relictos corroídos dentro de este mineral. Numerosos porfidoblastos de estaurolita euhedral de hasta $8 \mathrm{~mm}$ de longitud orientados al azar comúnmente exhiben núcleos con abundantes inclusiones orientadas de cuarzo e ilmenita, principalmente, y grafito, con bordes libres de inclusiones. Los patrones de inclusiones pueden ser rectos o sigmoidales y representan la fábrica más antigua identificada, la cual generalmente es discordante con la fábrica externa de la roca, sugiriendo que la estaurolita creció inter-cinemáticamente entre la segunda fase de deformación y la última. En algunos casos también es posible observar porfidoblastos de estaurolita con inclusiones orientadas al azar, desarrollando maclas cruciformes. Relictos corroídos de estaurolita son preservados en muscovita, de manera que el crecimiento de esta última claramente seria posterior al crecimiento de la estaurolita, aunque la muscovita es reemplazada por silimanita fibrolítica antes de la eliminación final de la estaurolita, la cual en algunos casos es parcialmente reemplazada por clorita y muscovita. Al parecer la estaurolita creció un tiempo después que el granate en estas rocas cuando estas habían alcanzado una temperatura más alta. La figura $2 \mathrm{~S}$, https://www.raccefyn.co/index.php/raccefyn/
article/downloadSuppFile/385/1919, ilustra algunos rasgos texturales observados no solo entre las rocas encajantes con venas de cuarzo (Figuras 2Sa-2Sd) sino también en el contacto entre las rocas encajantes y las KyQVs (Figuras $2 \mathrm{Se}-2 \mathrm{Sl}$ ). Las figuras $2 \mathrm{Sa}$ y $2 \mathrm{Sb}$ muestran un esquisto micáceo grafitoso con granate. El granate presenta numerosas inclusiones de cuarzo con un patrón sigmoidal y está envuelto por la matriz micácea desarrollando sombras de presión. Las figuras $2 \mathrm{Sc}$ y $2 \mathrm{Sd}$ ilustran un esquisto micáceo grafitoso con granate y estaurolita con esquistosidad de crenulación. El granate representa una variedad de tipo textural sector zonado y la estaurolita presenta un carácter poiquiloblástico con numerosas inclusiones de cuarzo, grafito e ilmenita. Cristales de biotita parcialmente alterados forman dominios lepidoblásticos que separan los agregados granoblásticos de cuarzo en la roca encajante (Figuras 2Se y 2Sf). Las figuras $2 \mathrm{Sg}$ y $2 \mathrm{Sh}$ ilustran la ocurrencia de un esquisto cuarzofeldespático, en el que se destaca la intensa alteración hidrotermal de la plagioclasa a sericita. En las figuras $2 \mathrm{Si} \mathrm{y}$ $2 \mathrm{Sj}$ se observa la ocurrencia de cristales de cianita dispuestos de manera paralela a la foliación de un esquisto micáceo con granate. Un intercrecimiento de cianita + cuarzo + plagioclasa se observa en las Figuras 2Sk y 2Sl. Obsérvese la intensa alteración de la plagioclasa a sericita. 


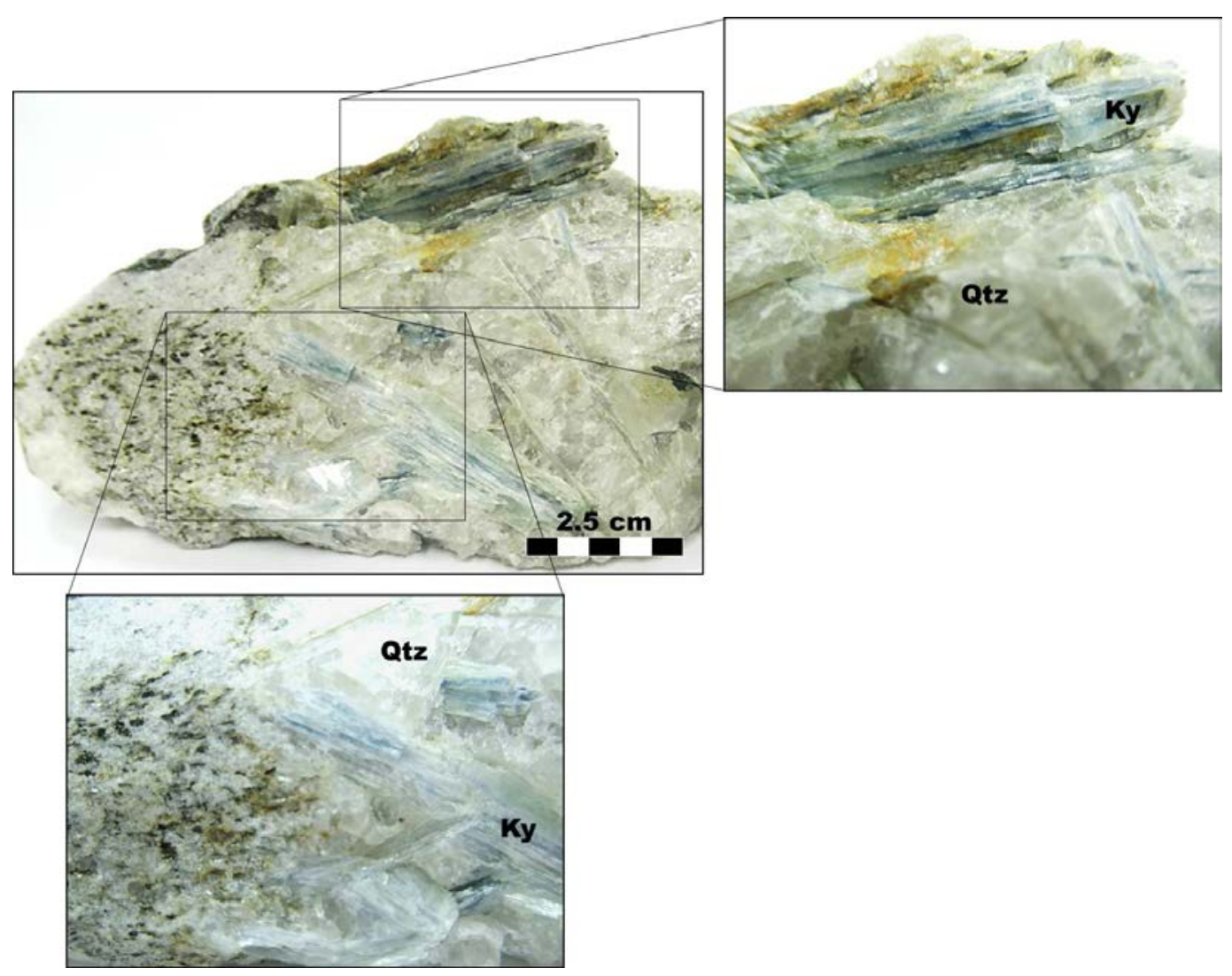

Figura 4. Espécimen de mano de KyQV de la zona de la estaurolita-cianita de la Formación Silgará, la cual engloba fragmentos de la roca encajante (parte inferior izquierda).

Petrografía de las KyQVs. La mineralogía de las KyQVs muestra algunas variaciones, aunque generalmente es el cuarzo el mineral dominante. La gran parte de las venas están compuestas de $70-90 \%$ de cuarzo, $0-25 \%$ de plagioclasa $\left(\mathrm{X}_{\mathrm{An}}\right.$ 0.34), $1-10 \%$ de cianita y $0-2 \%$ de muscovita. La cianita en estas venas puede variar en abundancia (1-10\%). Aunque como se mencionó previamente la muestra recolectada "ex situ" representa una vena compuesta casi en su totalidad por cianita, con andalusita y silimanita fibrolítica, y cuarzo en poca cantidad. Estas venas presentan además pocos óxidos (ilmenita) que generalmente ocurren dentro de las fracturas de las KyQVs. El cuarzo generalmente no muestra extinción ondulosa (evidencia de la ausencia de deformaciones dúctiles intracristalinas posteriores a su nucleación). La cianita puede observarse completamente inalterada, aunque comúnmente exhibe bordes de alteración a sericita o reemplazamiento en sus bordes y traza de exfoliación por muscovita. La figura 3S, https://www.raccefyn.co/index. php/raccefyn/article/downloadSuppFile/385/1920, ilustra algunos rasgos texturales observados en las KyQVs. Las figuras $3 \mathrm{Sa}$ y $3 \mathrm{Sb}$ ilustran el desarrollo poiquiloblástico de cianita alrededor de cuarzo. El contacto entre un esquisto biotítico cuarzoso con una vena de cuarzo se ilustra en las figuras $3 \mathrm{Sc}$ y $3 \mathrm{Sd}$. Obsérvese la biotita paralela a la esquistosidad principal de la roca. La cianita en las venas de cuarzo muestra dos rasgos distintivos; zonación de colores de absorción (Figuras 3Se y 3Sf) y deformación (pliegues tipo “kink") de la traza de exfoliación (Figuras 3Sg y 3Sh) en cristales individuales, caso similar a lo reportado por Ryan (2010). Beane and Field (2007) mapearon cristales individuales de cianita deformados mediante difracción de electrones retrodispersados para determinar el efecto de la deformación en la estructura cristalina. En el contacto entre las KyQVs y las rocas encajantes no se observan cambios mineralógicos y/o composicionales drásticos que reflejen una intensa interacción fluido-roca, excepto una delgada zona de transición en la que ocurre un enriquecimiento de muscovita y biotita.

La figura 4S, https://www.raccefyn.co/index.php/ raccefyn/article/downloadSuppFile/385/1921, ilustra algunas relaciones texturales observadas entre los polimorfos de $\mathrm{Al}_{2} \mathrm{SiO}_{5}$. La cianita ocurre como cristales subidioblásticos de alto relieve, exfoliación bien desarrollada y marcada, y partición basal perpendicular al clivaje que genera un aspecto fragmentado. La cianita se presenta en cristales orientados al azar, rodeando estaurolita en dominios ricos en cuarzo, indicando un crecimiento post-cinemático. Sin embargo, en dominios micáceos ocurre junto con muscovita y biotita, presentándose en cristales débilmente alineados que crecieron durante la formación de la fábrica dominante 
de la roca. La cianita generalmente exhibe bordes de reacción de sericita, los cuales han nucleado entre cianita y cuarzo, desarrollándose también pseudomorfos de sericita a partir de cianita. También es común encontrar cianita como relictos en muscovita. En otros casos, la cianita ha sido reemplazada por muscovita en sus bordes o siguiendo su traza de exfoliación. En algunos casos la cianita es reemplazada por silimanita fibrolítica. La andalucita ocurre como porfidoblastos euhedrales, de forma rectangular, alargados en el sentido de la foliación principal de la roca, los cuales pueden estar rodeados por cristales de cianita. Otra generación de andalucita corresponde a enormes neoblastos de carácter xenoblástico y poiquiloblástico, los cuales presentan numerosas inclusiones de cuarzo, principalmente, y minerales opacos, y que sugieren sobrecrecimiento postcinemático de la fábrica dominante de la roca. Los bordes de la andalucita son más irregulares que aquellos de la cianita, muchas veces debido a reemplazamiento por sericita.

La Figura 5S, https://www.raccefyn.co/index.php/ raccefyn/article/downloadSuppFile/385/1997, ilustra imágenes de electrones retrodispersados (BSE) obtenidas por microscopia electrónica de barrido (MEB), en las cuales se destaca a diferentes aumentos la morfología, exfoliación y partición de la cianita (Figuras 5Sa-5Sc), así como el espectro EDS (Energy Dispersive Spectroscopy) característico de la cianita (Figura 5Sd), el cual permite identificar semicuantitativamente su composición elemental con las proporciones relativas de cada elemento en el mineral analizado. El espectro EDS está de acuerdo con datos de la literatura (http://www.sfu.ca/ marshall/sem/mineral.htm).
El análisis EDS revela que la cianita presenta relaciones de masa de C:O:Al:Si de 14.67:43.82:27.97:13.54. La señal correspondiente al carbono (C) se atribuye al recubrimiento de carbono sobre la superficie de la muestra antes del análisis por MEB.

La figura 5 ilustra imágenes de electrones retrodispersados obtenidas por MEB, en las cuales se destacan las principales relaciones texturales de la cianita en la vena de cuarzo o en la zona de transición entre esta y la roca encajante. En las KyQVs, la muscovita generalmente se forma hacia los bordes y siguiendo la traza de exfoliación de la cianita (Figura 5a). Obsérvese como el contacto entre cianita y cuarzo a pesar del poco contraste de colores en la imagen de electrones retrodispersados puede definirse en base a la exfoliación y la fractura que exhiben la cianita y el cuarzo, respectivamente. En la zona de transición entre las KyQVs y la roca encajante, se destacan varios aspectos. La cianita ocurre como inclusiones en plagioclasa a la cual también puede bordear; la plagioclasa presenta además inclusiones de cuarzo e ilmenita (Figura 5b). Obsérvese el intercrecimiento entre cianita y muscovita en la parte inferior izquierda. La figura $5 \mathrm{c}$ ilustra la asociación mineral en la roca encajante, la cual se caracteriza por la presencia de cuarzo + plagioclasa + biotita + ilmenita. Un intercrecimiento entre cianita, cuarzo y plagioclasa es comúnmente observado hacia el contacto entre las KyQVs y la roca encajante (Figuras $5 \mathrm{~d}$ y $5 \mathrm{e})$. La ilmenita es el mineral accesorio. La figura $5 \mathrm{f}$ ilustra inclusiones de cuarzo, ilmenita y clorita en plagioclasa; la clorita se ha formado a expensas de la biotita, desarrollando un pseudomorfo.
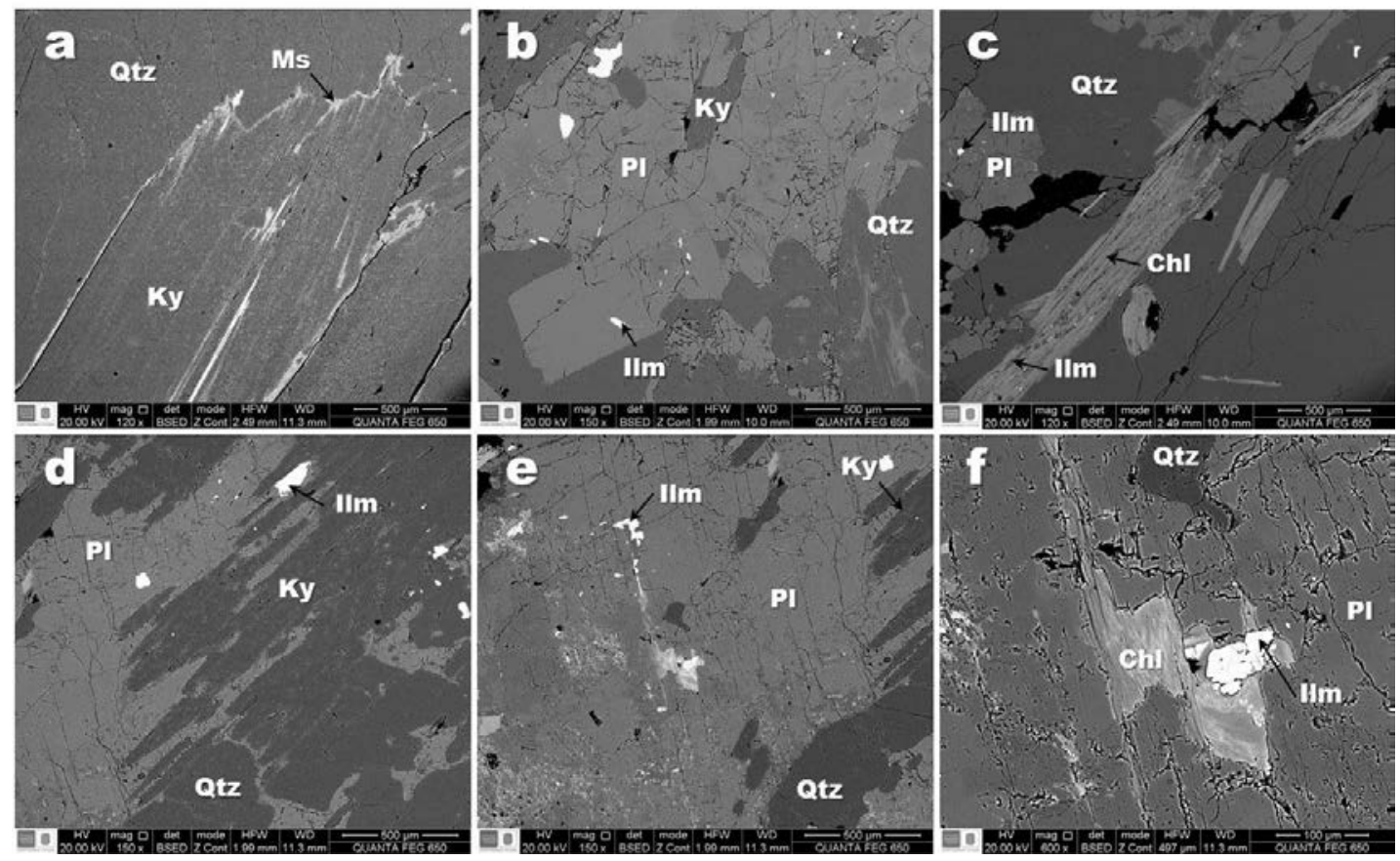

Figura 5. Imágenes de electrones retrodispersados al MEB ilustrando las principales relaciones texturales de la cianita dentro de la roca encajante o vena de cuarzo. 


\section{Discusión sobre la formación de las KyQVs}

Historia reaccional. La secuencia de reacciones minerales observadas en las rocas metapelíticas, que representan las rocas encajantes de las KyQVs, han sido documentadas por García, et al. (2005). A continuación, se discuten brevemente aquellas reacciones que involucran la presencia de los polimorfos de $\mathrm{Al}_{2} \mathrm{SiO}_{5}$ que ocurren en esquistos de la zona de la estaurolita-cianita. Evidencia textural indica una secuencia paragenética andalucita $\rightarrow$ cianita $\rightarrow$ silimanita fibrolítica, aunque es común la coexistencia entre cianita y andalucita, más no con silimanita, la cual representa una fase tardía. De otra parte, la reacción (1 soporta la primera aparición de cianita (isógrada de la cianita).

(1) andalucita = cianita.

La reacción (2) no debió haber ocurrido al mismo tiempo durante el metamorfismo, debido a que realmente se desconoce si la andalucita reaccionó directamente para producir silimanita o si fue primero disuelta en una fase fluida, la cual transportaba componentes disueltos a un nuevo sitio donde el fluido finalmente precipito silimanita fibrolítica. Relictos corroídos de cianita pueden haber sido formados como resultado de un proceso de disolución, el cual pudo afectar también a algunos cristales de cuarzo. En algunos casos la silimanita se formó dentro de cristales de muscovita.

(2) andalucita $=$ silimanita

La disolución de cianita en las rocas metapelíticas puede ser explicada a partir de la reacción retrógrada (3).

(3) cianita + cuarzo + fluido $(\mathrm{K})=$ muscovita

La disolución de muscovita en la roca encajante con la resultante formación de cianita en las venas de cuarzo podría explicarse a través de la reacción (4).

(4) muscovita $+\mathrm{H}^{+}=$cianita + cuarzo + fluido $(\mathrm{K})$

De esta manera, los tres polimorfos de $\mathrm{Al}_{2} \mathrm{SiO}_{5}$ pueden ocurrir. La silimanita fibrolítica podría representar la fase mineral más joven, la cual claramente esta sobreimpuesta a andalucita y cianita. Las rocas adyacentes a las venas hidrotermales pueden contener andalucita y cianita deformadas, extensamente reemplazadas por muscovita. Recristalización de muscovita a expensas de estaurolita o cianita ocurre comúnmente, y típicas texturas de esta etapa de recristalización están representadas por relictos corroídos de estos aluminosilicatos y de silimanita dentro de muscovita. Este crecimiento de muscovita parece estar relacionado a la alta actividad de agua y potasio en la fase fluida en la zona de estaurolita-cianita (Chinner, 1961). Estas texturas revelan la siguiente historia de crecimiento de los aluminosilicatos en la RCMS: (1) crecimiento de andalucita, (2) sobrecrecimiento de andalucita por cianita, (3) nueva formación de andalucita siguiendo la foliación metamórfica regional, (4) nueva formación de cianita siguiendo la foliación metamórfica regional, aunque, estos dos últimos eventos podrían asociarse al crecimiento de granate y estaurolita, (5) formación de cianita en venas de cuarzo, (6) crecimiento de silimanita fibrolítica. No obstante, estos dos últimos eventos podrían llegar a ser contemporáneos y asociados al emplazamiento de granitoides, como evidencia del magmatismo tardío ocurrido durante el evento orogenico menor Fammatiniano del Silúrico propuesto por Mantilla, et al. (2016). Las paragénesis con estaurolita-cianita se desarrollaron durante el pico de metamorfismo regional. Durante el levantamiento isotérmico, la circulación de fluidos localizados resultó en el desarrollo tardío de silimanita fibrolítica. Sin embargo, según García, et al. (2005), evidencia textural indica que, en contra de lo que se propone en el presente estudio, la andalucita es el polimorfo de $\mathrm{Al}_{2} \mathrm{SiO}_{5}$ más jóven, mientras que la cianita y la silimanita representarían, respectivamente, los picos bárico y térmico de metamorfismo. La otra posibilidad que se podría contemplar sería el efecto producido por los intrusivos graníticos de dimensiones batolíticas que podrían encontrarse en niveles estructurales poco profundos dentro de la secuencia metamórfica, los cuales obviamente representan un evento posterior al pico de metamorfismo. En este sentido, es necesario considerar que la roca hospedadora de las KyQVs refleja la transformación polimórfica de andalusita $\rightarrow$ cianita (pico bárico) $\rightarrow$ silimanita (pico térmico), con el desarrollo de porfidoblastos de andalusita y silimanita fibrolítica en una etapa tardía asociada al magmatismo tardío arriba señalado. No existe aún evidencia de la ocurrencia de andalucita o silimanita o ambas con cianita en venas de cuarzo, aunque si diferentes relaciones entre estos polimorfos de $\mathrm{Al}_{2} \mathrm{SiO}_{5}$ en rocas metapelíticas, siendo quizás la cianita y la silimanita dos fases minerales que se formarían por transformaciones polimórficas a partir de la nucleación en y alrededor de cristales de andalucita texturalmente más tempranos. No obstante, en la muestra "ex situ" es posible deducir la transformación polimórfica, en al cual se destaca la nucleación inicial de la cianita, cuando el ambiente frágil espaciado y acuoso facilitó el desarrollo de cristales de gran tamaño (hasta de $10 \mathrm{~cm}$ de logitud). Posterior a este evento, se sugiere una fase de descompresión en el sistema, debido a un proceso de levantamiento, que favoreció la nucleación de andalucita, seguida de una fase caracterizada por el aumento en las condiciones de presión y temperatura, por trasnporte tectónico a niveles más profundos de la corteza, durante el cual se llevó a cabo la nucleación de sillimanita fibrolítica a partir de sus dos predecesores, consumiendo el exceso de Al que se encontraba aún en el sistema. Cristales prismáticos de cianita ocurren en venas de cuarzo, generalmente siguiendo la foliación principal de la roca, aunque en una roca adyacente a una vena de cuarzo se ha comprobado la existencia de cianita, andalucita, estaurolita y granate, con la formación de silimanita fibrolítica tardía. Algunas venas de cuarzo pudieron desarrollarse en un contexto dúctil y que corresponden a la formación prógrada inicial de cianita por medio de la reacción polimórfica andalucita $\rightarrow$ cianita que se relacionan con niveles estructurales más profundos, mientras que otras pueden atribuirse a un contexto frágil en niveles estructurales poco profundos durante la exhumación.

El origen de las KyQVs ha sido propuesto por Kerrick (1990) como consecuencia de la circulación de paleofluidos que contienen $\mathrm{Al}$ y Si disueltos. Un mecanismo similar 
propuesto por otros autores (e.g., Carmichael, 1969; Foster, 1986; Cesare, 1994) explica el origen de segregaciones de aluminosilicatos dentro de rocas silicatadas. Cesare (1994) propone igualmente un mecanismo de hidrofracturamiento para explicar la ocurrencia de venas de cuarzo-biotitaandalucita en hornfelsas pelíticas en aureolas de contacto, considerando que el material fuente para la generación de dichas venas se derivó localmente de las rocas metapelíticas encajantes. Las venas de cuarzo en terrenos metamórficos regionales han sido interpretadas o como trayectorias fosilizadas de circulación de fluidos y transferencia de masa adyectiva a gran escala (e.g., Yardley, 1986; Ferry, 1992; Masters and Ague, 2005) o como segregaciones producidas por transporte local de Si (e.g., Yardley, 1975; Yardley and Bottrell, 1992) o una combinación de los dos. En principio podrían considerarse varias posibilidades para explicar el origen de las KyQVs en las rocas metapelíticas de la Formación Silgará, de acuerdo a modelos propuestos en otros estudios (e.g., Etheridge, et al., 1984; Kerrick, 1990; Ague, 1994a; 1994b), los cuales pueden involucrar fuentes externas de fluidos (sistema abierto) a través de procesos de infiltración o fuentes locales de fluidos (sistema cerrado) a través de procesos de difusión. Reacciones prógradas de deshidratación dentro de esquistos pelíticos en la zona de la estaurolita-cianita han sido quizás el mecanismo que produce las venas de cuarzo, las cuales usualmente presentan cianita. Beitter, et al. (2008) demostraron que grandes cantidades de $\mathrm{Al}$ transportadas en fluidos metamórficos regionales debido a su gran movilidad pueden promover la formación de KyQVs, probablemente independiente del contexto tectónico (ambiente frágil-dúctil) considerado. No obstante, hay que considerer además que estas podrían haberse formardo por diferenciación metamórfica, promoviendo la remobilización de Si de la roca encajante. Widmer and Thompson (2001), a partir de datos de balance de masa indican que no es necesario involucrar la circulación de fluidos de infiltración de fuentes distantes. En este sentido, las reacciones de deshidratación de silicatos, particularmente de la muscovita, han sido documentadas en el presente estudio. Puede suponerse que gradientes de potencial químico, principalmente de $\mathrm{Al}_{2} \mathrm{O}_{3}$, habrían favorecido la nucleación y el crecimiento de cianita en las venas de cuarzo a expensas de la descomposición de la muscovita en las paredes de la roca encajante, en este caso las rocas metapelíticas de la Formación Silgará. Según Widmer and Thompson (2001), el gradiente en el potencial químico del $\mathrm{Al}_{2} \mathrm{O}_{3}$ entre las fases reactantes en las rocas encajantes y las nuevas fases producidas (cianita + cuarzo) promueve el transporte de $\mathrm{Al}_{2} \mathrm{O}_{3}$ hacia la vena, proceso que se ilustra en la Figura 6. Los gradientes químicos resultan de la presencia de cuarzo + cianita en las venas y los reactantes (principalmente muscovita) en las rocas adyacentes. Este proceso puede explicarse en términos de dos reacciones, una en la roca encajante (5) y la otra en la vena de cuarzo (6).

(5) muscovita $=\mathrm{Al}_{2} \mathrm{O}_{3}(\mathrm{aq})+\mathrm{SiO}_{2}(\mathrm{aq})+\mathrm{H}_{2} \mathrm{O}$

(6) $\mathrm{Al}_{2} \mathrm{O}_{3}$ (aq) $+\mathrm{SiO}_{2}$ (aq) = cianita + cuarzo
Temporalidad de formación de las KyQVs. Las KyQVs al parecer no se correlacionan con la mineralogía o el grado de metamorfismo de la roca encajante. La presencia de cianita en las venas de cuarzo a diferencia de la ocurrencia de dos o incluso tres polimorfos de $\mathrm{Al}_{2} \mathrm{SiO}_{5}$ en las rocas metapelíticas encajantes no necesariamente refleja la falta de una interacción vena - roca encajante durante la cristalización de la vena hidrotermal ni una fuente externa de materiales potencialmente formadores de venas. Estas observaciones indican que diferentes mecanismos de formación de venas pudieron haber actuado en diferentes momentos de la evolución tectono-termal de estos materiales. Actualmente, no existe evidencia de la ocurrencia de andalucita y/o silimanita en venas de cuarzo encajadas en rocas con similar paragénesis mineral.

La presencia de cianita hacia la zona central de las venas de cuarzo se debe básicamente a la xxx durante eventos de rehidratación en un contexto frágil resultado de la exhumación del orógeno que dió origen a venas hidrotermales tardías paralelas a la foliación regional de las rocas metapelíticas (Caviedes y Gómez, 2006). La cianita ocurre también en contacto neto entre los esquistos micáceos (roca encajante) y las venas de cuarzo. Widmer and Thompson

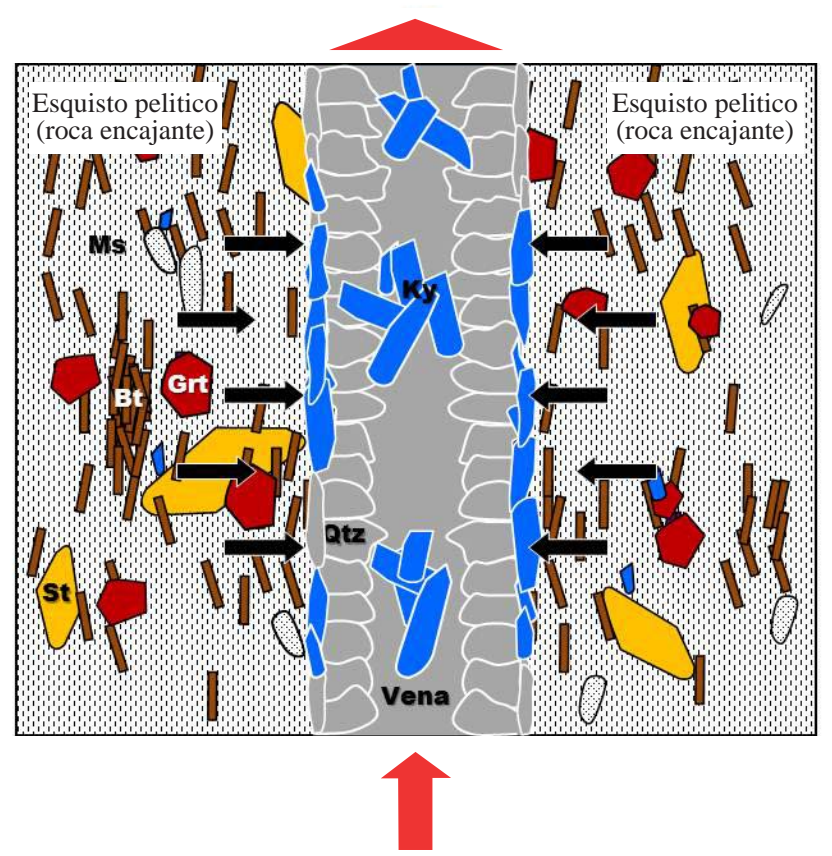

Flujo de fluido

Figura 6. Diagrama explicativo de los procesos químicos involucrados en la formación de las KyQVs (adaptado y modificado de Widmer and Thompson, 2001). La reacción discontinua que produce cianita es considerada por estos autores como la combinación de dos subreacciones: en los esquistos pelíticos, liberando $\mathrm{Al}_{2} \mathrm{O}_{3}$ y $\mathrm{SiO}_{2}$ al fluido hidrotermal, y en la vena, la cual hace que estas especies químicas sean disueltas para precipitar cianita. Las flechas mostradas en el esquema indican la dirección de difusión intergranular. 
(2001 reportan concentraciones de $\mathrm{Al}_{2} \mathrm{O}_{3}$ y $\mathrm{SiO}_{2}$, las cuales muestran una disminución sistemática en la roca encajante hacia estas venas, indicando significantes cambios en la concentración de varios elementos en las paredes de las rocas adyacentes a las KyQVs. La formación de KyQVs podría no haber involucrado la misma interacción con las rocas encajantes como ocurriría con los otros polimorfos, en caso de que estos evidentemente ocurran Según estos autores, la circulación de paleofluidos resultantes de la deshidratación de fases hidratadas (e.g., muscovita), acompañada de la disolución y el transporte de $\mathrm{Al}$ y $\mathrm{Si}$ a lo largo de gradientes de presión fluctuantes a través de las rocas en proceso de deshidratación, no explica sin embargo el porqué solo la cianita, y con frecuencia el cuarzo, y no el espectro completo de fases minerales de las rocas encajantes está presente en la región ahora ocupada por las KyQVs.

Aunque la edad geológica de la formación de las KyQVs estudiadas es incierta, las paragénesis minerales dentro de estas venas suponen su formación en condiciones de la facies de la anfibolita, debido a que grandes cantidades de Al pueden ser transportadas por fluidos metamórficos bajo estas condiciones (Beitter, et al., 2008). En nuestro caso, la posibilidad de descifrar la cronología relativa de los pulsos hidrotermales soportaría algunas hipótesis. Por lo tanto, aquí será fundamental hacer una reconstrucción de la historia hidrotermal de los paleofluidos que han circulado a través de una zona de cizallamiento (Caviedes y Gómez, 2006) como se describe abajo, los cuales son importantes, entre otros, como agentes de transporte de calor, removilización, transporte y depositación de elementos químicos. Las KyQVs encajadas en rocas metapelíticas de la Formación Silgará podrían reflejar la ocurrencia de una amplia zona de cizallamiento dúctil, la cual estaría soportada por la presencia de bandas de cizallamiento distribuidas, milonitas, estructuras s-c (aún no han sido estudiadas en detalle) asociadas con la recristalización mineral, lo cual indica que la deformación dúctil incluyendo cizallamiento tuvo lugar probablemente cerca a la zona de transición frágil-dúctil, a una profundidad aproximada de $10 \mathrm{~km}$. El tiempo exacto del metamorfismo de presión intermedia, acompañado de engrosamiento cortical debido a un evento colisional, como lo reportan García, et al. (2005), no ha sido establecido aun, pero los datos disponibles hasta ahora parecen indicar una fase orogénica mayor que ocurrió durante la orogénesis Fammatiniana principal del Ordovícico Temprano (Mantilla, et al., 2016). La formación de las KyQVs quizás no involucró el mismo tipo de interacción con las rocas encajantes que las venas con ausencia de este mineral, lo cual indica que diferentes mecanismos formadores de venas pudieron haber ocurrido a diferentes tiempos durante el metamorfismo dinamotérmico de esta unidad metamórfica (Caviedes y Gómez, 2006). Por lo tanto, el crecimiento tardío de cristales de cianita puede haber ocurrido en respuesta a un aumento de la presión y/o disminución de la temperatura, aunque las condiciones de presión y temperatura aun serían inciertas. En las rocas encajantes (esquistos micáceos principalmente) existe evidencia de transformaciones polimórficas, aunque las fases minerales de $\mathrm{Al}_{2} \mathrm{SiO}_{5}$ pudieron haberse igualmente formado a partir de otros minerales alumínicos. Según Sepahi, et al. (2004), la ocurrencia de diferentes secuencias de cristalización dentro de una región relativamente pequeña puede indicar que las trayectorias de PT pasaron cerca del punto triple de $\mathrm{Al}_{2} \mathrm{SiO}_{5}$ produciendo diferentes trayectorias evolutivas en rocas que experimentaron similares condiciones de metamorfismo. Por lo tanto, es muy probable que la trayectoria de PT propuesta por García, et al. (2005) para las rocas metapelíticas de la Formación Silgará no sea solo una, sino que las diferentes relaciones entre los polimorfos de $\mathrm{Al}_{2} \mathrm{SiO}_{5}$ permitirían sugerir el desarrollo de diferentes trayectorias alternativas, dependiendo de las transformaciones polimórficas que ocurran en una roca. Igualmente, debería considerarse la ocurrencia de un evento termal (¿metamorfismo de contacto?) sobre el evento de metamorfismo regional, combinado con la interacción fluido-roca asociada con la circulación de paleofluidos que pudieron haber favorecido una variedad de ambientes fisicoquímicos, con control estructural, en los cuales la nucleación de polimorfos de $\mathrm{Al}_{2} \mathrm{SiO}_{5}$ varió en gran proporción en las rocas encajantes. No es claro, sin embargo, si la ausencia de andalucita o silimanita o ambas en las KyQVs sea debida al carácter metastable que estas pueden llegar a tener en condiciones de PT favorables para la formación de cianita, la cual es el único polimorfo de $\mathrm{Al}_{2} \mathrm{SiO}_{5}$ observado en venas de cuarzo, a diferencia de lo que ocurre en otros contextos geológicos, en donde se reportan venas de cuarzo con presencia de uno, dos o tres de estos polimorfos. Es muy probable que fluidos acuosos a presiones intermedias hayan circulado a través de las rocas metapelíticas como consecuencia de la ocurrencia de reacciones químicas de deshidratación que promueven la disolución de fases minerales tales como la muscovita. Estos

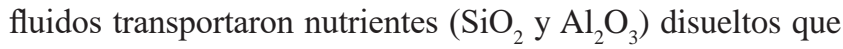
representan las fuentes para la formación de las KyQVs.

\section{Conclusiones}

El basamento metamórfico del Macizo de Santander presenta varios sectores con profusión de venas hidrotermales paralelas a la foliación metamórfica regional, las cuales de componen, en mayor o menor medida, de cuarzo, clorita, albita, y otros minerales que pueden ser relacionados en su formación con la circulación o el escape de fluidos metamórficos (considerados generalmente como neutros y reducidos, y derivados de reacciones metamórficas de deshidratación).

La presencia de venas hidrotermales (algo boudinadas) con cuarzo-cianita, paralelas a la foliación metamórfica regional de la Formación Silgará aflorante en el sector central del Macizo de Santander, al parecer es un caso excepcional, tanto por su restringida distribución en el contexto del MS (al menos por ahora), como por la naturaleza de los potenciales fluidos asociados a su formación (en términos generales ácidos y posiblemente también algo oxidantes). 
Con base en la información geológica disponible, se infiere que la formación de las venas de cuarzo-cianita en el área de estudio, este relacionada con fluidos derivados de procesos magmático-hidrotermales $(\mathrm{MH})$, cuya edad y cuerpo(s) ígneo(s) causativo(s) aún no han sido determinados, ni establecidos. Sin embargo, se sospecha que esos procesos $\mathrm{MH}$ podrían temporalmente estar asociados al emplazamiento de intrusiones ígneas de edad Ordovícico (generadores del protolito ígneo de la unidad Ortogneis)?.

Estudios posteriores más detallados sobre la fisicoquímica de los paleofluidos asociados a la formación de las venas de cuarzo-cianita objeto de estudio (entre otros tipos potenciales de venas temporalmente relacionadas, pero aún no reconocidas o documentadas) y sus posibles paleo-alteraciones hidrotermales asociadas, podrían ayudar a develar el potencial metalogénico de esos eventos paleohidrotermales en ese sector del MS.

\section{Agradecimientos}

Los autores agradecen a la Universidad Industrial de Santander por brindar el apoyo logístico para la realización del trabajo de campo con la participación de estudiantes de Geología de la asignatura Campo II, y el uso de diferentes técnicas analíticas. Agradecimientos al laboratorio de petrografía del Grupo de Investigación en Geología Básica y Aplicada de la Universidad Industrial de Santander y su personal, por el servicio de laboratorio y analítico suministrado para la adquisición de datos.

\section{Información suplementaria}

Figura 1S. Espécimen de mano de muestra "ex situ” ilustrando las relaciones texturales entre los polimorfos de $\mathrm{Al}_{2} \mathrm{SiO}_{5}$, así como intercrecimientos de cianita + muscovita sobre superficie pulida. Vea la figura 1S en: https:/www.raccefyn.co/index.php/raccefyn/ article/downloadSuppFile/385/1918

Figura 2S. Fotomicrografías ilustrando los rasgos texturales (a-d) entre las rocas encajantes con venas de cuarzo y (e-l) en el contacto entre las rocas encajantes y las KyQVs observados en PPL y XPL, respectivamente; Aumento 4x. Vea la figura $2 \mathrm{~S}$ en: https://www. raccefyn.co/index.php/raccefyn/article/downloadSuppFile/385/1919

Figura 3S. Fotomicrografías ilustrando la ocurrencia de cianita en la roca encajante y venas de cuarzo observados en PPL y XPL, respectivamente; Aumento 4x (a-d); 10x (e-h). Vea la figura 3S en: https://www.raccefyn.co/index.php/raccefyn/article/downloadSupp File/385/1920

Figura 4S. Fotomicrografías ilustrando las relaciones texturales observadas entre los polimorfos de $\mathrm{Al}_{2} \mathrm{SiO}_{5}$ en la muestra "ex situ" de la Figura 1S, así como intercrecimientos de cianita + muscovita observados en XPL; Aumento 4x. Vea la figura 4S en: https://www. raccefyn.co/index.php/raccefyn/article/downloadSuppFile/385/1921 Figura 5S. (a)-(c) Imágenes de electrones retrodispersados al MEB ilustrando a diferentes aumentos la morfología, exfoliación y partición de la cianita. (d) Espectro EDS característico de la cianita. Vea la figura 5S en: https:/www.raccefyn.co/index.php/raccefyn/ article/downloadSuppFile/385/1997

\section{Conflicto de intereses}

Los autores declaran no tener conflicto de intereses.

\section{Referencias}

Ague, J.J. (1994a). Mass transfer during Barrovian metamorphism of pelites, south-central Connecticut. I: evidence for changes in composition and volume. American Journal of Science, 294 (8): 989-1057.

Ague, J.J. (1994b). Mass transfer during Barrovian metamorphism of pelites, south-central Connecticut. II: channelized fluid flow and the growth of staurolite and kyanite. American Journal of Science, 294 (8): 1061-1134.

Ague, J.J. (1995). Deep-crustal growth of quartz, kyanite and garnet into large-aperture, fluid-filled fractures, north-eastern Connecticut, USA. Journal of Metamorphic Geology, 13 (2): 299-314.

Allaz, J., Maeder, X., Vannay, J. \& Steck, A. (2005). Formation of aluminosilicate-bearing quartz veins in the Simano nappe (Central Alps): structural, thermobarometric, and oxygen isotope constraints. Schweizerische Mineralogische und Petrographische Mitteilungen, 85 (2-3): 191-214.

Beane, R.J. \& Field, C.K. (2007). Kyanite deformation in whiteschist of the ultrahigh-pressure metamorphic Kokchetav Massif, Kazakhstan. Journal of Metamorphic, 25 (2): 117-128.

Beitter, T., Wagner, T. \& Markl, G. (2008). Formation of kyanite-quartz veins of the Alpe Sponda, Central Alps, Switzerland: implications for $\mathrm{Al}$ transport during regional metamorphism. Contributions to Mineralogy and Petrology, 156 (6): 689-707.

Boinet, T., Bourgois, J., Bellon, H. \& Toussaint, J. (1985). Age et repartition du magmatism Premesozoique des Andes de Colombie. Comptes rendus hebdomadaires des séaces de L'Académie des Sciences. Serie D: SciencesNaturalles, 300 (II): 445-450.

Botello, F., Mantilla, L.C. \& Colegial, J.D. (2014). Edad U-Pb en zircones y contexto tectónico de formación del Granito de Durania (Macizo de Santander, Colombia). Memorias XI Semana Técnica de Geología y I Geosciences anual meeting. UIS. Bucaramanga, 11 al 15 de Agosto de 2014.

Bucholz, C.E. \& Ague, J.J. (2010). Fluid flow and Al transport during quartz-kyanite vein formation, Unst, Shetland Islands, Scotland. Journal of Metamorphic Geology, 28 (1): 19-39.

Carmichael, D. (1969). On the mechanism of prograde metamorphic reactions in quartz-bearing pelitic rocks. Contribution to Mineralogy and Petrology, 20 (3): 244-267.

Campos, N. (1999). Estudio Mineralógico y Petrográfico de las Metamorfitas al Occidente del Municipio de Mutiscua (Norte de Santander). Tesis de Pregrado, Universidad Industrial de Santander, Bucaramanga (Colombia).

Castellanos, O.M. (2001). Chemical composition of the rockforming minerals in the Silgará formation and P-T conditions in the Mutiscua area, Santander Massif, Eastern Cordillera, Colombia. Unpublished Master Thesis, Shimane University, Matsue (Japan).

Castellanos, O.M., Ríos, C.A. \& Takasu A. (2004). Chemically sector-zoned garnets in the metapelitic rocks of the Silgará Formation in the central Santander Massif, Colombian Andes: occurrence and growth history. Boletín de Geología, 26 (1): 91-98. 
Castellanos, O.M., Ríos, C.A. \& Takasu A. (2008). A new approach on the tectonometamorphic mechanisms associated with $\mathrm{P}-\mathrm{T}$ paths of the Barrovian-type Silgará Formation at the Central Santander Massif, Colombian Andes. Earth Sciences Research Journal, 12 (2): 125-155.

Caviedes, M.A. \& Gómez, R.E. (2006). Petrogénesis de venas hidrotermales con cianita en rocas metapelíticas de la Formación Silgará, región central del Macizo de Santander. Tesis de Pregrado, Universidad Industrial de Santander, Bucaramanga (Colombia).

Cesare, B. (1994). Synmetamorphic veining: origin of andalusitebearing veins in the Vedrette di Ries contact aureole, eastern Alps, Italy. Journal of Metamorphic Geology, 12 (5): 643-653.

Chinner, G.A. (1961). The origin of sillimanite in Glen Clova, Angus. Journal of Petrology, 2 (3): 312-323.

Clavijo, J. (1994). Mapa geológico generalizado del Departamento de Norte de Santander, Memoria explicativa. Informe interno INGEOMINAS, 67p.

Cordani, U., Cardona, A., Jimenez, D., Liu, D. \& Nutman, A. (2005). Geochronology of Proterozoic basement inliers in Colombian Andes: tectonic history of remnants of a fragmented grenville belt. In: terrane processes at margins of gondwana. Geological Society, London, Special Publications. Edited by Vaughan, A., Leat, P., and Pankhurst, R., 246: 329-346.

Etheridge, M.A., Wall, V.J. \& Cox, S.F. (1984). High fluid pressures during regional metamorphism and deformation: implications for mass transport and deformation mechanisms. Journal of Geophysical Research, 89 (6): 4344-4358.

Ferry, J.M. (1992). Regional metamorphism of the Waits River Formation, eastern Vermont: Delineation of a new type of giant metamorphic hydrothermal system. Journal of Petrology, 33 (1): (4594).

Foster, C. (1986). Thermodynamic models of reactions involving garnet in sillimanite/staurolite schist. Mineralogical Magazine, 50: 427-439.

García, C.A., Ríos, C.A. \& Castellanos, O.M. (2005). Mediumpressure metamorphism in the central Santander Massif, Eastern Cordillera, Colombian Andes: constraints for a collision model. Boletín de Geología, 27 (2): 43-68.

Grant, J.A. (1986). The isocon diagram; a simple solution to Gresens'equation for metasomatic alteration. Economic Geology, 81 (8): 1976-1982.

Julivert, M. (1970). Cover and basement tectonics in the Cordillera Orientalof Colombia, South America, and a comparison with some other folded chains. Geological Society American Bulletin, 81: 3623-3643.

Kerrick, D. (1990). The $\mathrm{Al}_{2} \mathrm{SiO}_{5}$ polymorphs. Reviews in Mineralogy 22. Mineralogical Society of America, Washington, D.C., 406p.

Kretz, R. (1983). Symbols for rock-forming minerals. American Mineralogist, 68: 277-279.

Lentz, D.R. \& Gregoire, C. (1995). Petrology and mass-balance constraints on major-, trace- and rare-earth-element mobility in porphyry-greisen alteration associated with epizonal True Hill granite, south-western New Brunswick, Canada. Journal of Geochemical Exploration, 52 (3): 303-331.

Lang, H.D. \& Dunn, G.R. (1990). Sequential porphyroblast growth during deformation in a low pressure metamorphic terrane, Orrs Island, Haspswell Neck, Maine. Journal of Metamorphic Geology, 8 (2): 199-216.
Larson, T.E. \& Sharp, Z.D. (2003). Stable isotopic constraints on the Al2SiO5 "triple point” rocks from the Proterozoic Priest pluton contact aureole, New Mexico, USA. Journal of Metamorphic Geology, 21 (8): 785-798.

Mantilla, L.C., Ríos, C.A., Gélvez, J.R., Márquez, R.E., Ordoñez, J.C. \& Cepeda, S. (2003). Nuevas evidencias acerca de la presencia de una banda de cizallamiento en la Formación Silgará del sector Aratoca-Pescadero (Macizo de Santander). Boletín de Geología, 25 (40): 81-90.

Mantilla, L.C., Bissig, T., Cottle, J.M. \& Hart, C. (2012). Remains of early Ordovician mantle-derived magmatism in the Santander Massif (Colombian Eastern Cordillera). Journal of South American Earth Sciences, 38: 1-12.

Mantilla, L.C., García, C.A. \& Valencia, V. (2016). Propuesta de escisión de la denominada 'Formación Silgará' (Macizo de Santander, Colombia) a partir de edades $\mathrm{U}-\mathrm{Pb}$ en circones detríticos. Boletín de Geología, 38 (1): 33-50.

Masters, R.L. \& Ague, J.J. (2005). Regional-scale fluid flow and element mobility in Barrow's metamorphic zones, Stonehaven, Scotland. Contributions to Mineralogy and Petrology, 150: 1-18.

McLelland, J., Morrison, J., Selleck, B., Cunningham, B., Olson, C. \& Schmidt, K. (2002). Hydrothermal alteration of late- to post- tectonic Lyon Mountain granitic gneiss, Adirondack Mountains, New York: origin of quartzsillimanite segregations, quartz-albite lithologies, and associated Kiruna-type low-Ti-Fe-oxide deposits. Journal of Metamorphic Geology, 20 (1): 175-190.

Nabelek, P. (1997). Quartz-sillimanite leucosomes in high-grade schists, Black Hills, South Dakota: a perspective on the mobility of $\mathrm{Al}$ in high-grade metamorphic rocks. Geology, 25 (11): (995-998).

Okayuma-Kusunose, Y. (1994). Phase relations in andalusitesillimanite type Fe-rich metapelites; Tono contact metamorphic aureole, Northeast Japan. Journal of Metamorphic Geology, 12 (2): 153-168.

Putlitz, B., Valley, J.W., Matthews, A. \& Katzir, Y. (2002). Oxygen isotope thermometry of quartz- $\mathrm{Al}_{2} \mathrm{SiO}_{5}$ veins in high-grade metamorphic rocks on Naxos island (Greece). Contributions to Mineralogy and Petrology, 143 (3): 350-359.

Restrepo-Pace, P.A. \& Cediel, F. (2010). Northern South America basement tectonics and implications for paleocontinental reconstructions of the Americas. Journal of South American Earth Sciences, 29: 764-771.

Royero, J. \& Clavijo, J. (1994). Mapa Geológico generalizado departamento de Santander. Escala 1: 400.000. Informe INGEOMINAS, 92p.

Ryan, N.A. (2010). Microstructures of a deformed kyanite-quartz vein of the Raft River Mountains in northwest Utah, USA. Undergraduate Thesis of Bachelor of Arts, Carleton College, Northfield, Minnesota.

Sepahi, A.A., Whitney, D.L. \& Baharifar, A.A. (2004). Petrogenesis of andalusite-kyanite-sillimanite veins and host rocks, Sanandaj-Sirjan metamorphic belt, Hamadan, Iran. Journal of Metamorphic Geology, 22 (2): 119-134.

Silva, J.C., Sial, A.N., Ferreira, V.P. \& Estrada, J.J. (2004). C-isotope stratigraphy of a Vendian carbonate succession in northwestern Andes: Implications for the NW Andes. In: IV Reunión Ciencias de la Tierra, Querétaro (México), Abstracts, vol. 198. 
Spear, J.A. (1982). Metamorphism of pelitic rocks of the Snyder Group in the contact aureole of the Kiglapait layered intrusión, Labrador: effect of buffering partial pressures of wáter. Canadian Journal of Earth Sciences, 19 (10): 1888-1909.

Stout, M.Z., Crawford, M.L. \& Ghent, E.D. (1986). Pressuretemperature evolution of fluid compositions of $\mathrm{Al}_{2} \mathrm{SiO}_{5}-$ bearing rocks, Mica Creek, B.C. in light of fluid inclusion data and mineral equilibrium. Contributions to Mineralogy and Petrology, 92 (2): 236-247.

Thompson, A.B. (1975). Calc-silicate diffusion zones between marble and pelitic schist. Journal of Petrology, 16 (1): 314346.

Van der Lilej, R., Spikings, R., Ulianov, A., Chiaradia, M. \& Mora, A. (2016). Palaeozoic to Early Jurassic history of the northwestern corner of Gondwana, and implications for the evolution of the Iapetus, Rheic and Pacific Oceans. Gondwana Research, 31: 271-294.

Verdes, G., Gout, R. \& Castet, S. (1992). Thermodynamic properties of the aluminate ion and of bayerite, boemite, diaspore, and gibbsite. European Journal of Mineralogy, 4 (4): 767-792.

Ward, D.E., Goldsmith, R., Cruz, B.J., Jaramillo, C.L. \& Vargas, L.R. (1970). Mapa Geológico del Cuadrángulo H-13, Pamplona, Colombia. Ingeominas.

Ward, D.E., Goldsmith, R., Cruz, B.J., Jaramillo, C.L. \& Restrepo, H. (1973). Geología de los Cuadrángulos H-12,
Bucaramanga y H-13, Pamplona, Departamento de Santander. U.S. Geological Survey e Ingeominas. Boletín Geológico, XXI (1-3): 1-132.

Widmer, T. \& Thompson, A. (2001). Local origin of high pressure vein material in eclogite facies of the Zermatt-Saas Zone, Switzerland. American Journal of Science, 301 (7): 627-656.

Whitney, D.L. \& Dilek, Y. (2000). Andalusite-sillimanite-quartz veins as indicators of low-pressure-high-temperature deformation during late-stage unroofing of a metamorphic core complex, Turkey. Journal of Metamorphic Geology, 18 (1): 59-66.

Yardley, B.W.D. (1975). On some quartz-plagioclase veins in the Connemara schists, Ireland. Geological Magazine, 112: 183-190.

Yardley, B.W.D., Leake, B.E. \& Farrow, C.M. (1980). The metamorphism of Fe-rich pelites from Connemara, Ireland. Journal of Petrology, 21 (2): (365-399).

Yardley, B.W.D. (1986). Fluid migration and veining in the Connemara Schists, Ireland. In J.V. Walther and B.J. Wood, Eds., Fluid-rock Interactions During Metamorphism: Springer-Verlag, New York p. 109-131.

Yardley, B.W.D. \& Bottrell, S.H. (1992). Silica mobility and fluid movement during metamorphism of the Connemara schists, Ireland. Journal of Metamorphic Geology, 10 (3): 453-464. http://www.sfu.ca/ marshall/sem/mineral.htm. Mineral Energy Dispersive Spectra (EDS) Consulted on 15 September, 2014. 